\title{
Association of type 2 diabetes mellitus with self- reported knee pain and clinical knee osteoarthritis: The Maastricht Study
}

Citation for published version (APA):

Nielen, J. T. H., Emans, P. J., van den Bemt, B., Dagnelie, P. C., Schram, M. T., Stehouwer, C. D. A., Schaper, N. C., Denissen, K. F. M., de Vries, F., \& Boonen, A. (2018). Association of type 2 diabetes mellitus with self-reported knee pain and clinical knee osteoarthritis: The Maastricht Study. Diabetes \& Metabolism, 44(3), 296-299. https://doi.org/10.1016/j.diabet.2018.01.013

Document status and date:

Published: 01/06/2018

DOI:

10.1016/j.diabet.2018.01.013

Document Version:

Publisher's PDF, also known as Version of record

Document license:

Taverne

Please check the document version of this publication:

- A submitted manuscript is the version of the article upon submission and before peer-review. There can be important differences between the submitted version and the official published version of record.

People interested in the research are advised to contact the author for the final version of the publication, or visit the DOI to the publisher's website.

- The final author version and the galley proof are versions of the publication after peer review.

- The final published version features the final layout of the paper including the volume, issue and page numbers.

Link to publication

\footnotetext{
General rights rights.

- You may freely distribute the URL identifying the publication in the public portal. please follow below link for the End User Agreement:

www.umlib.nl/taverne-license

Take down policy

If you believe that this document breaches copyright please contact us at:

repository@maastrichtuniversity.nl

providing details and we will investigate your claim.
}

Copyright and moral rights for the publications made accessible in the public portal are retained by the authors and/or other copyright owners and it is a condition of accessing publications that users recognise and abide by the legal requirements associated with these

- Users may download and print one copy of any publication from the public portal for the purpose of private study or research.

- You may not further distribute the material or use it for any profit-making activity or commercial gain

If the publication is distributed under the terms of Article 25fa of the Dutch Copyright Act, indicated by the "Taverne" license above, 


\section{Association of type 2 diabetes mellitus with self- reported knee pain and clinical knee osteoar- thritis: The Maastricht Study}

\section{Introduction}

Osteoarthritis $(\mathrm{OA})$ of the knee is a progressive disabling joint disease characterized by pain and functional limitations. The global age-standardized prevalence of radiographic knee OA in 2010 was estimated to be $3.8 \%$, and was higher in women $(4.8 \%)$ than in men $(2.8 \%)$ [1].

Several epidemiological studies have identified a strong association between type 2 diabetes mellitus (T2DM) and knee $\mathrm{OA}[2,3]$. As both diseases share overweight and obesity as strong common risk factors, one of the main underlying mechanisms causing $\mathrm{OA}$ in T2DM patients is thought to be the increased mechanical load on weight-bearing joints, especially the knees. However, the above-mentioned studies have shown that T2DM may be an independent risk factor for OA, suggesting a coexisting metabolic cause. Conversely, other studies have reported no independent association between T2DM and OA [4,5].

The mechanisms underlying pain in knee OA are still poorly understood. Perception of pain in patients with T2DM might be different partly because of their different underlying biopathology (formation of neurovascular channels in subchondral bone and articular cartilage, low-grade inflammation) and partly related to diabetic neuropathy. Therefore, it would be of value to understand whether the level of knee pain experienced by patients with T2DM is different from that of those without T2DM.

Thus, the primary aim of the present study was to evaluate the association of T2DM with knee pain and clinical knee OA. In addition, a further aim was to determine whether patients with T2DM experience different levels of pain compared with people without T2DM.

\section{Methods}

The Maastricht Study is an observational, prospective, population-based cohort study, the details of which have been published elsewhere [6]. The present report includes cross-sectional data from the first 3451 participants who completed the baseline survey between November 2010 and September 2013. The study has the approval of the institutional medical ethics committee (NL31329.068.10) and Dutch Ministry of Health, Welfare and Sport (Permit 131088-105234-PG). All participants gave their written informed consent. Information regarding drug use was available from electronic dispensing records obtained from community pharmacies. Participants not consenting to collection of their pharmacy data $(n=163)$, and those with type 1 diabetes mellitus
(T1DM; $n=43$ ) or missing data for any of the covariates $(n=507)$, were excluded, leaving a total of 2738 participants (Fig. 1 ).

Glucose metabolism status was defined, as per the World Health Organization (WHO) 2006 criteria, by a 2-h oral glucose tolerance test (OGTT) after an overnight fast. In addition, participants taking an antihyperglycaemic drug [AD; Anatomical Therapeutic Chemical Classification System (ATC) code A10] [7] were categorized as T2DM patients regardless of glucose levels. The date of the OGTT was used as the date of inclusion. T2DM patients were stratified by $\mathrm{HbA}_{1 \mathrm{c}}(\leq 6.0 \%, 6.1-7.0 \%,>7.0 \%)$ and by duration of $\mathrm{AD}$ treatment.

The presence of knee pain was assessed by simply asking participants whether their knee pain, which could not be due to an accident, was present for at least four of the previous six weeks (yes/no). Clinical knee OA was defined based on a modified version of the American College of Rheumatology (ACR) guidelines (Table $\mathrm{S} 1$; see supplementary materials associated with this article online) [8]. Participants should have experienced knee pain, and at least three of the following five criteria should apply: age $>50$ years; morning stiffness (lasting $<30 \mathrm{~min}$ ); bony tenderness; bony distortion; and no palpable warmth in the knee. In addition, participants with knee prostheses were classified as having knee OA. Severity of knee pain was scored on a visual analogue scale (VAS) ranging from 0 to 10 , with 0 corresponding to "no pain" and 10 reflecting "pain as bad as it possibly could be". Subjects missing data for any outcome were excluded from analyses of that outcome, thereby leaving a final total $n=2719$ for knee pain analysis and $n=2721$ for knee OA analysis (Fig. 1).

Logistic regression models were fitted to test the association between T2DM and knee pain or clinical knee OA. Odds ratios (ORs) and $95 \%$ confidence intervals (CIs) were assessed in unadjusted models and in models adjusted for body mass index (BMI). Subsequently, our analyses were also adjusted for age, gender and BMI. Finally, our fully adjusted models included the following confounders:

- age, gender, BMI, systolic (SBP) and diastolic blood pressure (DBP), smoking status, level of education, alcohol use, a physically demanding occupation and a history of activities such as running and/or jumping;

- and use of the following drugs in the six months prior to inclusion: statins, diuretics, calcium-channel blockers, betablockers, renin-angiotensin-aldosterone system (RAAS) inhibitors, paracetamol, non-steroidal anti-inflammatory drugs (NSAIDs), opioids, bisphosphonates and systemic corticoids.

The association of T2DM with severity of self-reported knee pain in patients with clinical knee OA was assessed using a linear regression model, adjusted for the same above-mentioned confounders as in the fully adjusted logistic regression model and complemented by the following covariates: previous knee 


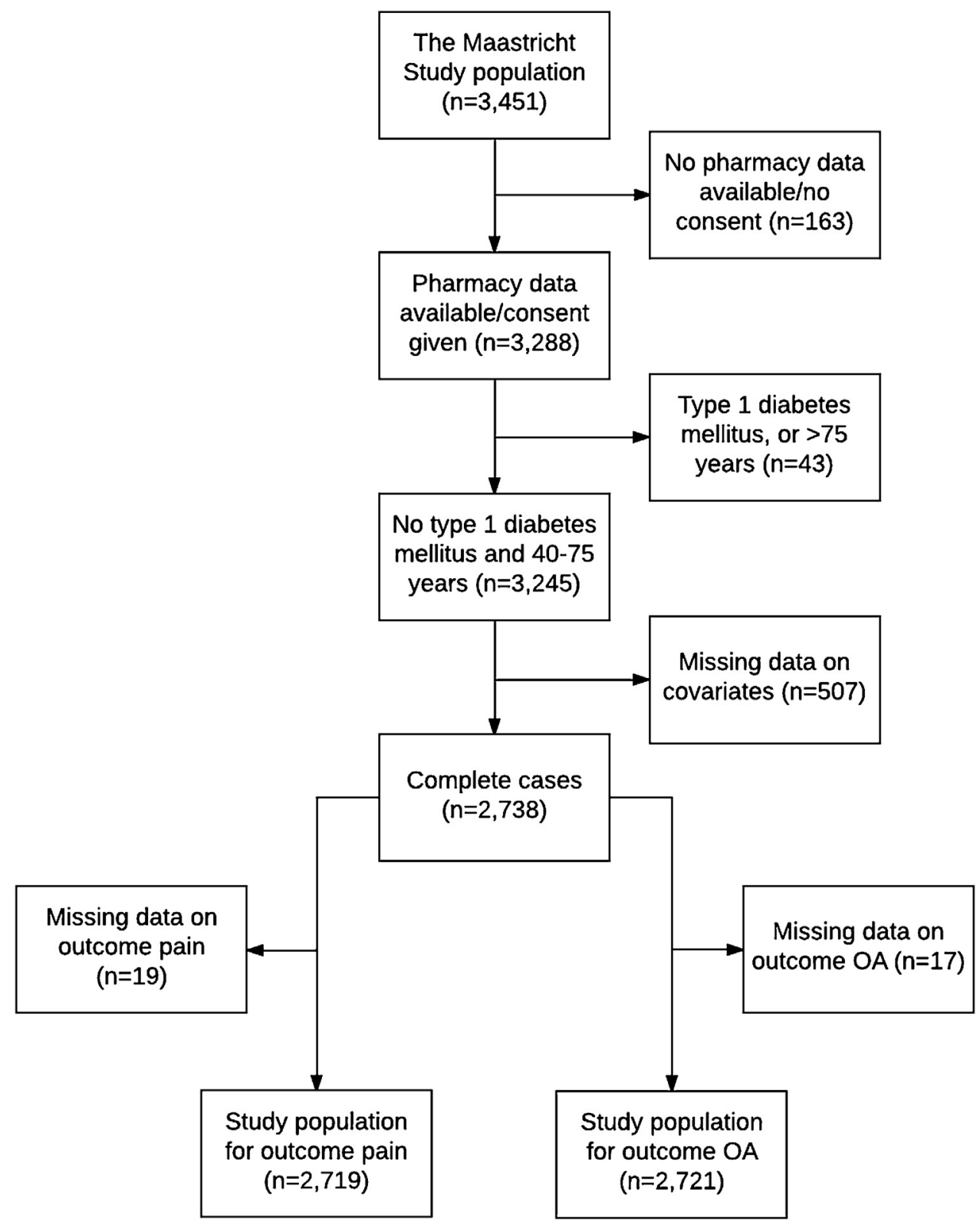

Fig. 1. Flow chart of inclusion of study participants.

surgery; previous sports-related knee injury; presence of neuropathic pain [four-item Neuropathic Pain Questionnaire (DN4) score $\geq 3$ ], and knee alignment (valgus/varus). Statistical significance was set at $P<0.05$, and SAS version 9.4 software (SAS Institute, Cary, NC, USA) was used for all analyses.

\section{Results}

From the study base population of 3451 participants, 2719 and 2721 cases with no missing data were available for the knee pain and knee OA analyses, respectively (Fig. 1). For the former analysis, $549 / 2719(20.2 \%)$ subjects fulfilled the case definition, as did 387/ 2721 (14.2\%) subjects for the latter analysis (Table S2; see supplementary materials associated with this article online). Participants with knee pain were, on average, 1 year older than those without knee pain (60.6 vs 59.8 years), whereas participants with knee OA were, on average, two years older than those without knee OA (62.3 vs 59.6 years). Also, participants with knee OA or knee pain had higher BMI scores than those without knee OA or knee pain. The age and gender standardized rate of OA in T2DM patients was $21.5 / 100$ population compared with $12.4 / 100$ population without T2DM. The age and gender distribution of the population without T2DM was used as reference (results not shown).

Compared with having normal glucose metabolism (NGM), T2DM was not associated with knee pain after adjusting for all relevant confounders (OR: $0.89,95 \% \mathrm{CI}$ : 0.67-1.19). Stratification of T2DM patients by $\mathrm{HbA}_{1 \mathrm{c}}$ or duration of $\mathrm{AD}$ use showed similar results (Table $S 3$; see supplementary materials associated with this article online). Similarly, T2DM was not associated with knee OA after adjusting for BMI (OR: 1.22, 95\% CI: 0.94-1.60). In addition, after adjusting for other relevant confounders, T2DM results showed no relevant changes (OR: 0.96, 95\% CI: 0.69-1.33). Stratification of T2DM patients by $\mathrm{HbA}_{1 \mathrm{c}}$ or duration of $\mathrm{AD}$ use showed similar results (Table 1 ).

Severity of knee pain was rated by $327 / 387$ (84.5\%) patients with knee $\mathrm{OA}$, and the results were $5.1 \pm 2.0$ [standard deviation (SD)] and $4.8 \pm 2.2$ in patients with and without T2DM, respectively. 
Table 1

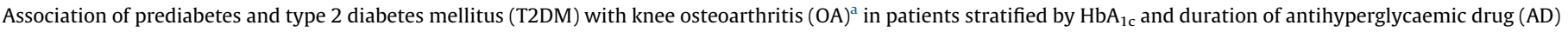
use.

\begin{tabular}{|c|c|c|c|c|c|c|}
\hline & $\begin{array}{l}\text { No knee OA } \\
(n=2334) \\
n(\%)\end{array}$ & $\begin{array}{l}\text { Knee OA } \\
(n=387) \\
n(\%)\end{array}$ & $\begin{array}{l}\text { OR }(95 \% \mathrm{CI}) \\
\text { unadjusted }\end{array}$ & $\begin{array}{l}\text { OR }(95 \% \mathrm{CI}) \\
\text { adjusted for BMI }\end{array}$ & $\begin{array}{l}\text { OR }(95 \% \mathrm{CI}) \\
\text { adjusted for } \\
\text { age/gender/BMI }\end{array}$ & $\begin{array}{l}\text { OR }(95 \% \mathrm{CI}) \text { fully } \\
\text { adjusted }^{\mathrm{b}}\end{array}$ \\
\hline$N G M$ & 1383 (59.3) & $182(47.0)$ & Reference & Reference & Reference & Reference \\
\hline Prediabetes & $363(15.6)$ & $65(16.8)$ & $1.36(0.99-1.85)$ & $1.09(0.80-1.49)$ & $0.97(0.70-1.35)$ & $0.98(0.70-1.37)$ \\
\hline$T 2 D M$ & $588(25.2)$ & $140(36.2)$ & $1.81(1.42-2.30)$ & $1.22(0.94-1.60)$ & $1.11(0.84-1.48)$ & $0.96(0.69-1.33)$ \\
\hline \multicolumn{7}{|l|}{$\mathrm{HbA}_{1 \mathrm{c}}$ levels: } \\
\hline$\leq 6.0 \%$ & $94(16.0)$ & $17(12.1)$ & $1.37(0.80-2.36)$ & $1.07(0.62-1.86)$ & $1.00(0.57-1.76)$ & $0.84(0.47-1.50)$ \\
\hline $6.1-7.0 \%$ & $324(55.1)$ & $68(48.6)$ & $1.59(1.18-2.16)$ & $1.10(0.80-1.52)$ & $0.97(0.69-1.37)$ & $0.86(0.59-1.26)$ \\
\hline$>7.0 \%$ & $170(28.9)$ & $55(36.2)$ & $2.46(1.75-3.46)$ & $1.55(1.07-2.25)$ & $1.47(0.99-2.17)$ & $1.28(0.83-1.98)$ \\
\hline \multicolumn{7}{|l|}{$A D$ use $e^{c}$} \\
\hline Never & $155(26.4)$ & $31(22.1)$ & $1.52(1.00-2.30)$ & $1.1(0.67-1.60)$ & $0.90(0.57-1.40)$ & $0.87(0.55-1.38)$ \\
\hline Past & $24(4.1)$ & $6(4.3)$ & $1.90(0.77-4.71)$ & $1.2(0.49-3.15)$ & $1.10(0.43-2.85)$ & $0.95(0.36-2.48)$ \\
\hline Recent & $25(4.3)$ & $5(3.6)$ & $1.52(0.57-4.02)$ & $1.3(0.49-3.50)$ & $1.16(0.43-3.16)$ & $1.04(0.37-2.92)$ \\
\hline Current & $384(65.3)$ & $98(70.0)$ & $1.94(1.48-2.54)$ & $1.3(0.96-1.74)$ & $1.21(0.88-1.66)$ & $1.01(0.70-1.47)$ \\
\hline \multicolumn{7}{|l|}{ Duration of $A D$ use } \\
\hline$\leq 879$ days & $101(26.3)$ & $20(20.4)$ & $1.50(0.91-2.49)$ & $1.0(0.61-1.74)$ & $1.01(0.59-1.73)$ & $0.87(0.49-1.55)$ \\
\hline $880-1645$ days & $97(25.3)$ & $23(23.5)$ & $1.80(1.11-2.91)$ & $1.2(0.72-1.98)$ & $1.13(0.67-1.92)$ & $0.99(0.56-1.73)$ \\
\hline 1646-2939 days & $96(25.0)$ & $25(25.5)$ & $1.98(1.24-3.15)$ & $1.3(0.82-2.16)$ & $1.26(0.76-2.08)$ & $1.05(0.60-1.83)$ \\
\hline > 2939 days & $90(23.4)$ & $30(30.6)$ & $2.53(1.63-3.94)$ & $1.6(1.04-2.62)$ & $1.45(0.89-2.35)$ & $1.17(0.68-2.02)$ \\
\hline
\end{tabular}

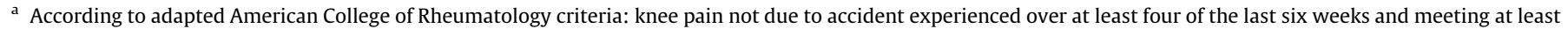

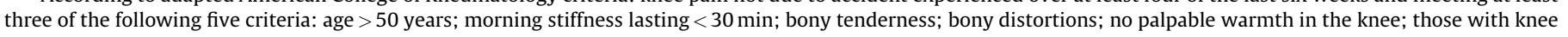
prostheses were classified as knee OA.

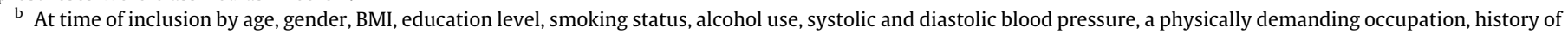

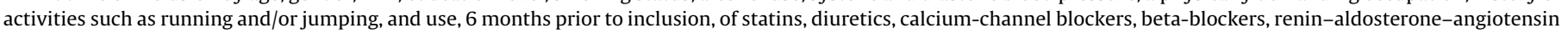
system (RAAS) inhibitors, paracetamol, non-steroidal anti-inflammatory drugs (NSAIDs), opioids, bisphosphonates or systemic corticoids.

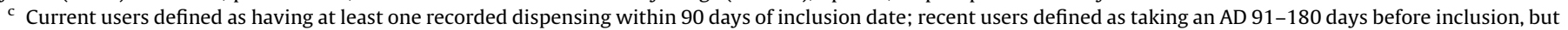
not within 90 days of inclusion date; past users defined as stopping AD use > 180 days before inclusion date; NGM: normal glucose metabolism.

Furthermore, T2DM did not contribute to the variable severity of knee pain in either unadjusted $(\beta: 0.28 ; P=0.23)$ or adjusted $(\beta:-0.04$; $P=0.88$ ) models (Table S4; see supplementary materials associated with this article online).

\section{Discussion}

Our present results demonstrate that patients with T2DM are more likely to experience knee pain and knee OA. However, these associations were no longer present after adjusting for BMI, reflecting the importance of overweight in the relationship between T2DM and knee pain or knee OA. In patients with knee $\mathrm{OA}$, there was no difference in severity of knee pain experienced by T2DM patients compared with those without T2DM.

The association of T2DM with knee pain as reported in the present study confirms the findings of previous studies $[9,10]$. The association of T2DM with knee OA was strongly influenced by BMI, suggesting that T2DM does not affect knee OA independently. The inconsistency between results from the present study and other previous studies may be due to methodological differences, such as different definitions of $\mathrm{OA}$, and the general difficulty of assessing duration and date of onset of knee OA and T2DM. Also, the known major role of overweight in knee OA might overrule (small) metabolic effects, although this may not apply to OA in other joints, such as those of the hand, where overweight is less likely to have any effect.

Although T2DM patients experience knee pain more often than those without T2DM, our study has shown that the severity of the experienced knee pain in patients with knee OA does not differ between subjects with and without T2DM. This may be due to the fact that our included T2DM population was relatively healthy, and their glucose metabolism was relatively well controlled. Thus, the effects of any underlying biopathological mechanisms or of diabetic neuropathy may have been limited.

Our study has several strengths. First, the Maastricht Study is characterized by an extensive phenotyping approach, making it possible to include a wide range of potential confounders. This provides an opportunity to better assess the independent association of T2DM with knee pain and knee OA. Second, as the Maastricht Study was focused on T2DM and its comorbidities, glucose metabolism status was highly accurately defined, rendering the risk of misclassification low. Third, this was the first study to provide an insight into the different perception of severity of knee pain between those with and without T2DM.

However, there were some limitations as well. Due to the crosssectional design of our study, causality cannot be assessed. Furthermore, as there was no measurement of crepitus during motion, the original ACR definition of clinical knee OA could not be used [8]. Nevertheless, our adapted definition was more stringent than the original (three out of five criteria were required compared with three out of six criteria in the original definition). Thus, some OA cases may have been misclassified as non-OA. However, such misclassification would be expected to be non-differential, resulting in a bias towards null. As a consequence, the effect of T2DM on OA may have been underestimated. Finally, as is the case in most studies, the date of onset and duration of T2DM are difficult to determine. In the present study, an attempt was made to approximate these data by stratifying T2DM patients by duration of AD use. However, this approximation may not reflect the actual date of disease onset as non-pharmacological lifestyle changes are usually suggested first. Nevertheless, it does provide a specific point in the course of the disease at which metabolic control can only be achieved by pharmacological treatment. Duration of knee pain or knee $O A$ were not available and were therefore not included in our analyses.

In conclusion, T2DM patients are more likely to experience knee pain or have knee OA compared with patients with NGM, although this seems to be mostly associated with overweight rather than a metabolic effect, thereby emphasizing the importance of weight reduction as a major factor in the treatment and prevention of knee pain and knee OA. Furthermore, T2DM patients with knee OA do not experience knee pain any differently from knee OA patients without T2DM. 


\section{Author contributions}

JN, AB, PE, BB, PD and FV contributed to the conception and design of the study. FV, PD, MS, AB, PE, NS and CS contributed to the acquisition of data. JN and KD contributed to analysis of data. All authors contributed to interpretation of data. JN, AB, NS and PE drafted the manuscript and all authors contributed intellectual content in revising the article. All authors gave final approval of the version to be submitted, and agreed to be accountable for all aspects of the work, ensuring that questions related to the accuracy or integrity of any part of the work are appropriately investigated and resolved.

\section{Disclosure of interest}

BB's department received research grants from Pfizer and Roche, and he has occasionally received speaker's honoraria from Pfizer, Roche, AbbVie and MSD. AB's department received research grants from Amgen, AbbVie, Pfizer and Merck, and she has occasionally received speaker's honoraria from Pfizer, UCB and Sandoz. PE's department receives research grants from Stryker, Active Implants, Episurf Medical, DSM Biomedical, Regentis Biomaterials, DePuy Synthes and he has occasionally received speaker's honoraria from Biomet. PD has received unrestricted grants from NWO, the EU and the nutritional industry for research unrelated to this topic. The other authors declare that they have no competing interest.

\section{Acknowledgements}

The Maastricht Study was supported by the European Regional Development Fund via OP-Zuid, the Province of Limburg, Dutch Ministry of Economic Affairs (grant 310.041), Stichting De Weijerhorst (Maastricht, the Netherlands), the Diabetes String of Pearls Initiative (Amsterdam, the Netherlands), the Cardiovascular Center (CVC, Maastricht, the Netherlands), CARIM School for Cardiovascular Diseases (Maastricht, the Netherlands), CAPHRI School for Public Health and Primary Care (Maastricht, the Netherlands), NUTRIM School for Nutrition and Translational Research in Metabolism (Maastricht, the Netherlands), Stichting Annadal (Maastricht, the Netherlands), Health Foundation Limburg (Maastricht, the Netherlands) and unrestricted grants from Janssen-Cilag B.V. (Tilburg, the Netherlands), Novo Nordisk Farma B.V. (Alphen aan den Rijn, the Netherlands), Sanofi-Aventis Netherlands B.V. (Gouda, the Netherlands) and the Dutch Arthritis Foundation (Reumafonds). We thank all participants of the Maastricht Study and their community pharmacists, and Apothekers Vereniging Maastricht and Verenigde Apotheken Limburg for their cooperation. Prof. Boonen is the guarantor of this paper.

\section{Appendix A. Supplementary data}

Supplementary data associated with this article can be found, in the online version, at https://doi.org/10.1016/j.diabet.2018.01. 013.

\section{References}

[1] Cross M, Smith E, Hoy D, Nolte S, Ackerman I, Fransen M, et al. The global burden of hip and knee osteoarthritis: estimates from the global burden of disease 2010 study. Ann Rheum Dis 2014;73:1323-30.

[2] Nieves-Plaza M. Association of hand or knee osteoarthritis with diabetes mellitus in a population of Hispanics from Puerto Rico. J Clin Rheumatol 2013;19:1-6.

[3] Schett G, Kleyer A, Perricone C, Sahinbegovic E, Iagnocco A, Zwerina J, et al. Diabetes is an independent predictor for severe osteoarthritis: results from a longitudinal cohort study. Diabetes Care 2013;36:403-9.

[4] Nielen JT, Emans PJ, Dagnelie PC, Boonen A, Lalmohamed A, de Boer A, et al. Severity of diabetes mellitus and total hip or knee replacement: a populationbased case-control study. Medicine (Baltimore) 2016;95:e3739.

[5] Frey N, Hügle T, Jick SS, Meier CR, Spoendlin J. Type II diabetes mellitus and incident osteoarthritis of the hand: a population-based case-control analysis. Osteoarthritis Cartilage 2016;24:1535-40.

[6] Schram MT, Sep SJ, van der Kallen CJ, Dagnelie PC, Koster A, Schaper N, et al. The Maastricht study: an extensive phenotyping study on determinants of type 2 diabetes, its complications and its comorbidities. Eur J Epidemiol 2014:29:439-51.

[7] WHO Collaborating Centre for Drug Statistics Methodology. ATC/DDD Index 2017. Accessible through: https://www.whocc.no/atc_ddd_index/.

[8] Altman R, Asch E, Bloch D, Bole G, Borenstein D, Brandt K, et al. Development of criteria for the classification and reporting of osteoarthritis. Classification of osteoarthritis of the knee. Diagnostic and Therapeutic Criteria Committee of the American Rheumatism Association. Arthritis Rheum 1986;29:1039-49.

[9] Molsted S, Tribler J, Snorgaard O. Musculoskeletal pain in patients with type 2 diabetes. Diabetes Res Clin Pract 2012;96:135-40.

[10] Pai LW, Hung CT, Li SF, Chen LL, Chung Y, Liu HL. Musculoskeletal pain in people with and without type 2 diabetes in Taiwan: a population-based, retrospective cohort study. BMC Musculoskelet Disord 2015;16:364.

J.T.H. Nielen ${ }^{\mathrm{a}, \mathrm{b}, \mathrm{c}, \mathrm{g}}$, P.J. Emans ${ }^{\mathrm{d}}$, B. van den Bemt ${ }^{\mathrm{e}, \mathrm{f}, \mathrm{g}}$, P.C. Dagnelie ${ }^{\mathrm{a}, \mathrm{c}, \mathrm{h}}$, M.T. Schram ${ }^{h, i, j}$, C.D.A. Stehouwer ${ }^{h, i}$, N.C. Schaper ${ }^{c, h, i}$, K.F.M. Denissen ${ }^{\mathrm{a}, \mathrm{c}}$, F. de Vries ${ }^{\mathrm{b}, \mathrm{g}}$, A. Boonen ${ }^{\mathrm{c}, \mathrm{k}, *}$ ${ }^{a}$ Department of Epidemiology, Maastricht University, $6200 \mathrm{MD}$ Maastricht, The Netherlands ${ }^{\mathrm{b}}$ Division of Pharmacoepidemiology and Clinical Pharmacology, Utrecht Institute of Pharmaceutical Sciences, 3508 TB Utrecht, The Netherlands ${ }^{\mathrm{C}}$ Care and Public Health Research Institute (CAPHRI), 6229 ER Maastricht University, Maastricht, The Netherlands

${ }^{\mathrm{d}}$ Department of Orthopaedics, Maastricht University Medical Centre, 6202 AZ Maastricht, The Netherlands e Department of Pharmacy, Sint Maartenskliniek, 6500 GM Nijmegen, The Netherlands

${ }^{f}$ Department of Pharmacy, Radboud University Medical Centre, $6500 \mathrm{HB}$ Nijmegen, The Netherlands

${ }^{\mathrm{g}}$ Department of Clinical Pharmacy and Toxicology, Maastricht University Medical Centre+, 6202 AZ Maastricht, The Netherlands

${ }^{\mathrm{h}}$ School for Cardiovascular Diseases (CARIM), Maastricht University, 6229 ER Maastricht, The Netherlands

i Department of Internal Medicine, Maastricht University Medical Centre+, 6202 AZ Maastricht, The Netherlands

${ }^{\mathrm{j}}$ Heart and Vascular Centre, Maastricht University Medical Centre+, 6202 AZ Maastricht, The Netherlands

${ }^{\mathrm{k}}$ Department of Internal Medicine, Division of Rheumatology, Maastricht University Medical Centre+, 6202 AZ Maastricht, The Netherlands

*Corresponding author. Department of Internal Medicine, Division of Rheumatology, Maastricht University Medical Centre+, P. Debyelaan 25, 6229 HX Maastricht, The Netherlands E-mail address: a.boonen@mumc.nl (A. Boonen).

Received 10 November 2017 Received in revised form 8 January 2018 Accepted 14 January 2018 Available online 3 February 2018 